\title{
Development of an Accident Consequence Assessment Code for Evaluating Site Suitability of Light- and Heavy-water Reactors Based on the Korean Technical Standards
}

\author{
Won Tae Hwang*, Hae Sun Jeong, Hyo Joon Jeong, A Reum Kil, Eun Han Kim, Moon Hee Han \\ Nuclear Environment Safety Research Division, Korea Atomic Energy Research Institute, Daejeon, Korea
}

\section{Original Research}

Received July 17, 2015

Revision October 13, 2016

Accepted October 31, 2016

Corresponding author: Won Tae Hwang

Korea Atomic Energy Research Institute, 111 Daedeok-daero 989beon-gil, Yuseong-gu, Daejeon 34057, Korea Tel: +82-42-868-2344,

Fax: $+82-42-868-2370$

E-mail:wthwang@kaeri.re.kr

This is an Open-Access article distributed under the terms of the Creative Commons Attribution NonCommercial License (http://creativecommons.org/ licenses/by-nc/4.0) which permits unrestricted noncommercial use, distribution, and reproduction in any medium, provided the original work is properly cited.

Copyright $\odot 2016$ The Korean Association for Radiation Protection

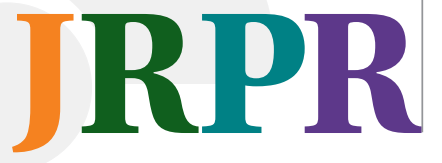

Background: Methodologies for a series of radiological consequence assessments show a distinctive difference according to the design principles of the original nuclear suppliers and their technical standards to be imposed. This is due to the uncertainties of the accidental source term, radionuclide behavior in the environment, and subsequent radiological dose. Both types of PWR and PHWR are operated in Korea. However, technical standards for evaluating atmospheric dispersion have been enacted based on the U.S. NRC's positions regardless of the reactor types. For this reason, it might cause a controversy between the licensor and licensee of a nuclear power plant.

Materials and Methods: It was modelled under the framework of the NRC Regulatory Guide 1.145 for light-water reactors, reflecting the features of heavy-water reactors as specified in the Canadian National Standard and the modelling features in MACCS2, such as atmospheric diffusion coefficient, ground deposition, surface roughness, radioactive plume depletion, and exposure from ground deposition.

Results and Discussion: An integrated accident consequence assessment code, ACCESS (Accident Consequence Assessment Code for Evaluating Site Suitability), was developed by taking into account the unique regulatory positions for reactor types under the framework of the current Korean technical standards. Field tracer experiments and hand calculations have been carried out for validation and verification of the models.

Conclusion: The modelling approaches of ACCESS and its features are introduced, and its applicative results for a hypothetical accidental scenario are comprehensively discussed. In an applicative study, the predicted results by the light-water reactor assessment model were higher than those by other models in terms of total doses.

Keywords: Accident consequence assessment, Site suitability, Technical standards

\section{Introduction}

Nuclear power plant (NPP) construction or operation licensing is subject to a safety analysis wherein it should be proven that the radiation-induced health risks to the public resulting from atmospheric releases are low enough in the event of an design-basis accident that may occur during NPP operation. An NPP safety analysis includes the evaluation of potential exposure resulting from the atmospheric behavior of radioactive materials released from the NPP. Technical standards for such evaluation vary substan- 
tially depending on the design and regulatory principles of the countries supplying nuclear power. The methodologies for a design-basis accident consequence assessment of lightand heavy-water reactors are presented in the Regulatory Guide by the U.S. Nuclear Regulatory Commission (NRC) and in the Canadian National Standard, respectively [1, 2]. These two types of reactors are different in many aspects, including methods for prediction of source terms released to the environment, methods and assumptions for atmospheric dispersion evaluation, selection of atmospheric dispersion factors to be used in evaluation, exposure pathways considered, and the site criteria in terms of radiological doses. Despite such differences, the Korean regulation presently applies the same methodologies, which is based on the Pressurized Water Reactor (PWR). The differences between the technical standards of the two reactor types are mainly attributed to the uncertainty of source terms in an accident and radionuclide behavior released to the environment.

In this study, an Accident Consequence Assessment Code for Evaluating Site Suitability (ACCESS) was developed. It reflects the assessment features applicable to light- and heavywater reactors in compliance with the technical standards of Korea. The following sections describe the features of the ACCESS code and the results of applying it to accident scenarios.

\section{Materials and Methods}

In Korea, the assessment methods of atmospheric dispersion factors in an accidental release of NPP are specified in

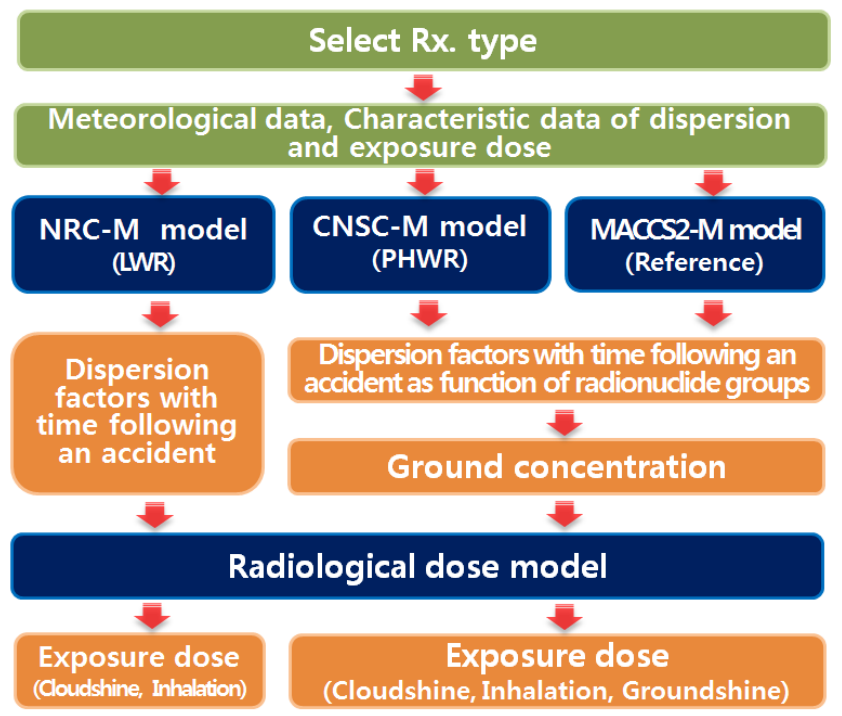

Fig. 1. Schematic diagram of ACCESS code.
Notification No. 2014-25 of the Nuclear Safety and Security Commission [3], and they have been fundamentally established under the technical standards for light-water reactors. The ACCESS code was configured to enable the accident consequence assessment of both light- and heavy-water reactors. It was modelled under the framework of the NRC Regulatory Guide 1.145 for light-water reactors, reflecting the features of heavy-water reactors as specified in the Canadian National Standard and the modelling features in MACCS2 [4], such as atmospheric diffusion coefficient, ground deposition, surface roughness, radioactive plume depletion, and exposure from ground deposition. Figure 1 shows a schematic block diagram of the ACCESS code.

As shown in the block diagram, the user can choose one from either light-water reactor assessment model (NRC-M) or heavy-water reactor assessment model (CNSC-M). Additionally, a model which contains features recommended in a probabilistic accident consequence assessment code (MACCS2-M) can be selected for comparison with the predicted results of a different model. A straight-line Gaussian plume model is used to evaluate atmospheric dispersion factor. Figure 2 shows a computational process of atmospheric dispersion factors for ground release hypothetical accidents. Atmospheric dispersion factors are evaluated through comparison between the equations according to atmospheric conditions as described in the NRC Regulatory

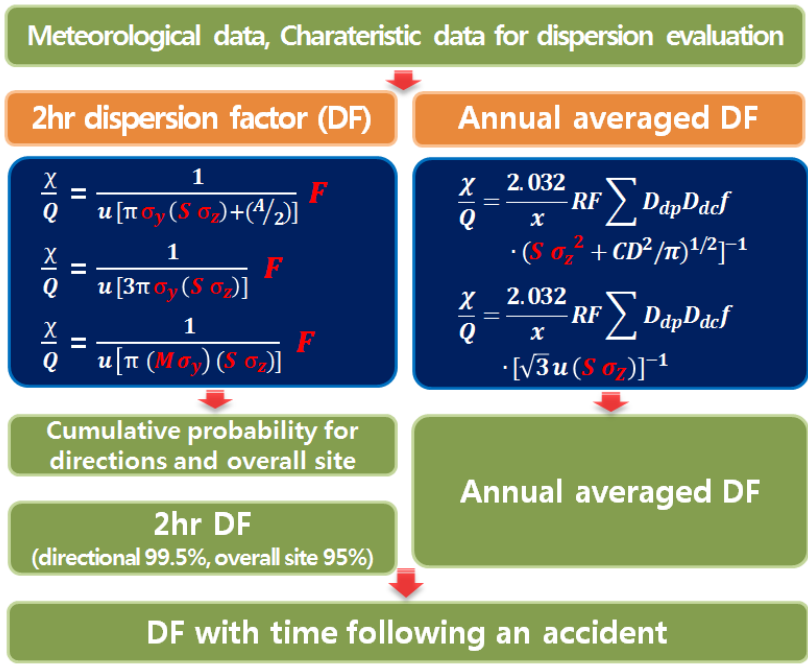

Fig. 2. Computational process of atmospheric dispersion factors $\left(\mathrm{X} / \mathrm{Q}\right.$ is atmospheric dispersion factor in $\mathrm{sec} \cdot \mathrm{m}^{-3}$; $\mathrm{u}$ is wind speed in $\mathrm{m} / \mathrm{sec}^{-1} ; \sigma_{y}$ and $\sigma_{z}$ are horizontal and vertical diffusion coefficients in meter, respectively; $S$ is surface roughness in meter; and $M$ and $F$ are correction factors for meandering and plume depletion due to ground deposition, respectively). 


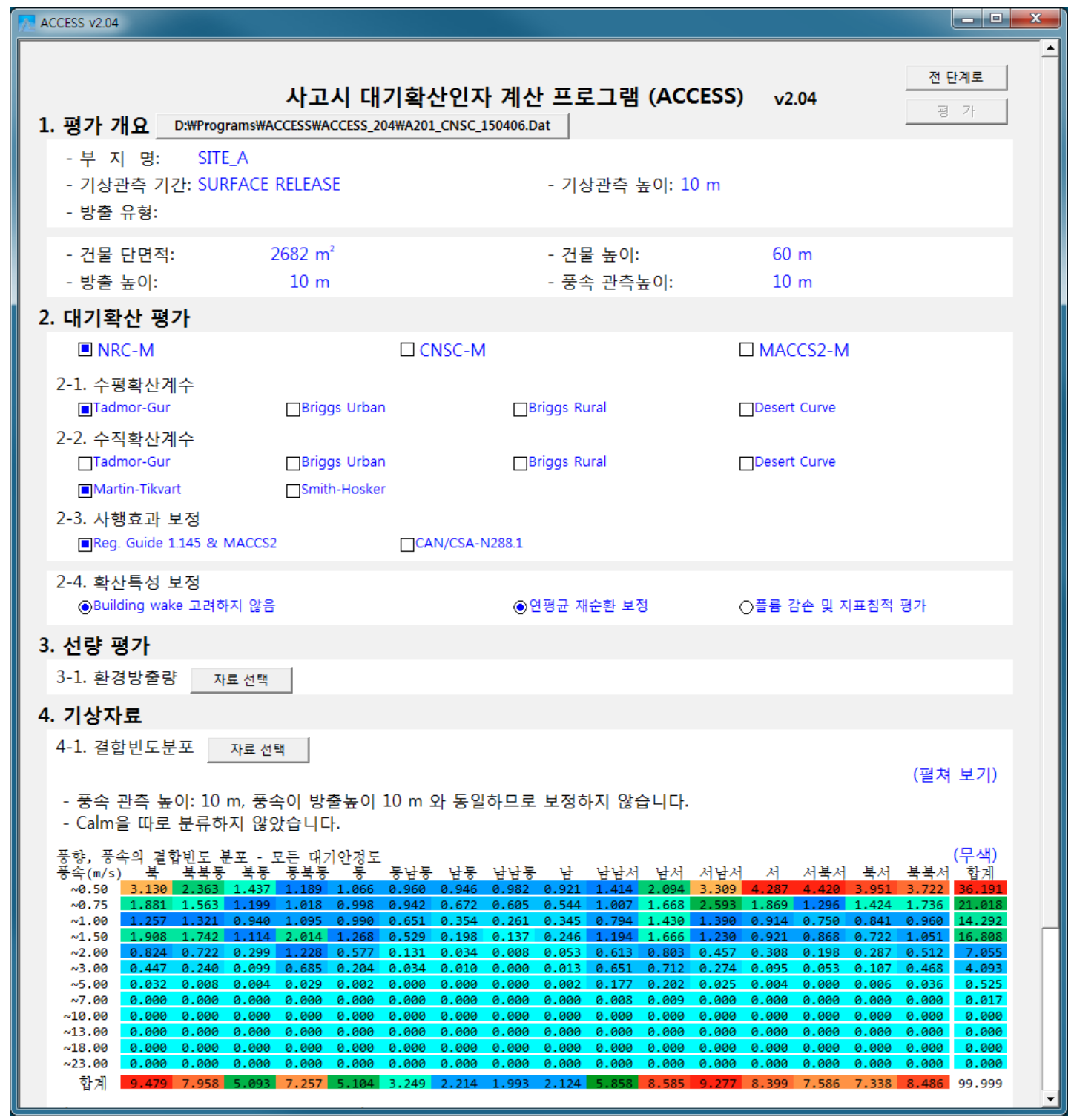

Fig. 3. Data input screen of ACCESS code.

Guide 1.145. Red-colored symbols in the equations are the parameters which are dependent on reactor types.

The computational process yields the atmospheric diffusion factors with time following an accident, and subsequent radiological doses as a function of radionuclide and exposure pathway. Dose coefficients based on the International Commission on Radiological Protection (ICRP) Publication 60[5] are contained in the ACCESS code as a data library, allowing the selection of chemical type of radionuclides released to the environment.

Figure 3 shows the input screen of the ACCESS code. On selecting the reactor type, the user is led to the default selection of the recommended model and parameters, or the user can directly select the model and parameters. Figure 4 shows the output screen of the ACCESS code. Outputs are atmospheric dispersion factors with time following an accident, and effective dose and thyroid dose according to exposure pathways and radionuclides released to the environment.

In the Wolseong NPP site, field experiments were performed under adverse meteorological conditions (stable atmosphere and low wind speed) 4 times (six air samplings each at 10 min intervals). $\mathrm{SF}_{6}$ was released as a trace gas. The values measured in the experiment and predicted by the model were then compared each other for model validation. Furthermore, hand calculations were performed for the verification of calculation results. 


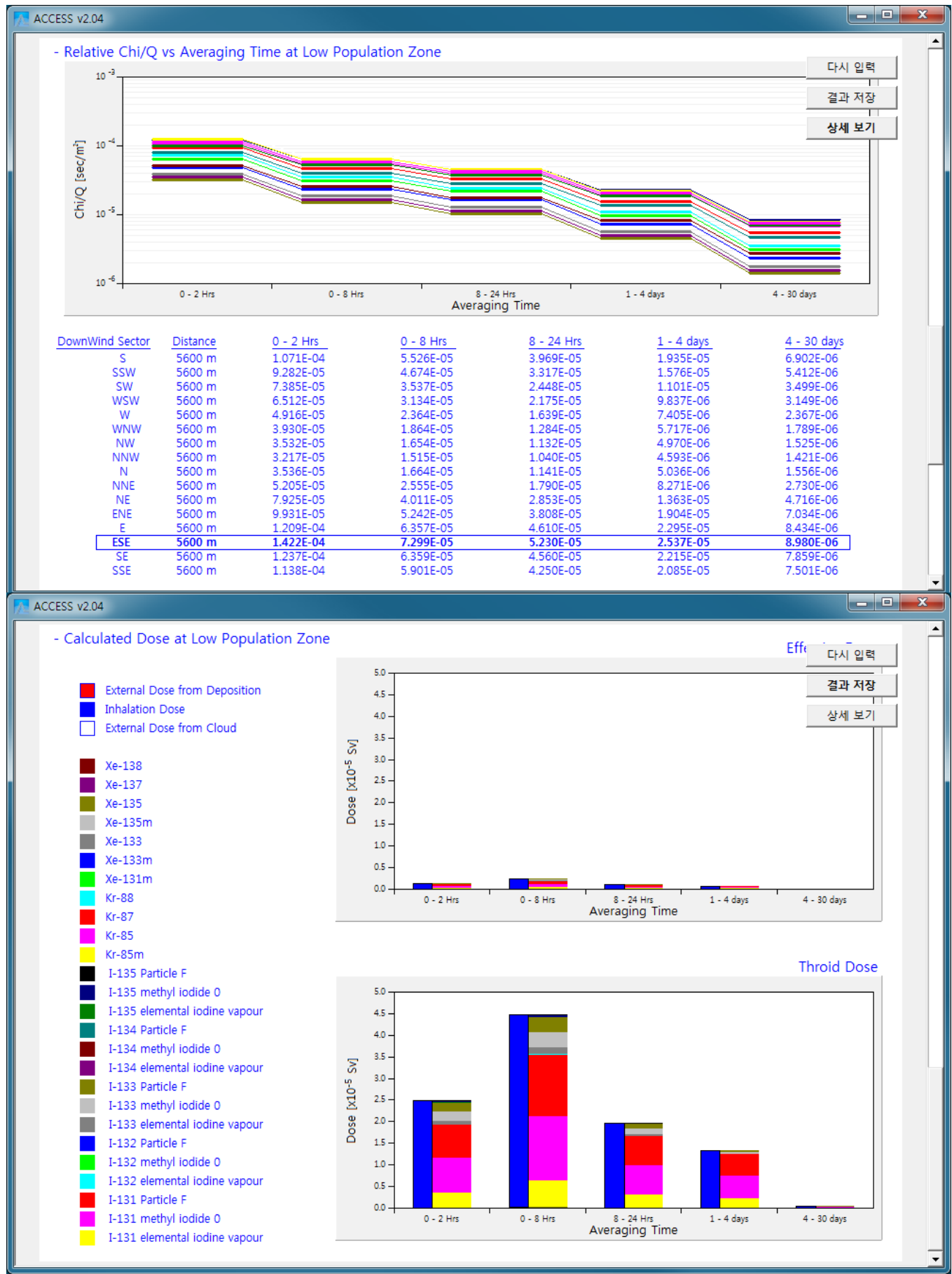

Fig. 4. Output screen of ACCESS code.

\section{Results and Discussion}

The performance of the code was tested for environmental release during the first $2 \mathrm{hr}$ after a large break loss-of-coolant accident. Source term is based on a traditional assessment methodology (TID-14844) for a light-water reactor (APR-
1400). The meteorological data measured for 3 consecutive years (2008-2010) at 10m height of the Wolsong NPP meteorological tower was used for the test. The environmental release of iodine, which might be a crucial contributor to health risk for humans, was assumed to be $100 \%$ elemental type. Table 1 presents the exposure doses applied to the 3 
Table 1. Exposure Dose According to Different Models

\begin{tabular}{|c|c|c|c|c|c|c|c|c|}
\hline \multirow{2}{*}{ Model } & \multicolumn{4}{|c|}{ Effective dose (mSv) } & \multicolumn{4}{|c|}{ Thyroid dose (mSv) } \\
\hline & Cloudshine & Inhalation & Groundshine & Total & Cloudshine & Inhalation & Groundshine & Total \\
\hline NRC-M & 28.2 & 132 & - & 160 & 30.0 & 2,500 & - & 2,530 \\
\hline CNSC-M & 22.3 & 71.5 & 2.71 & 96.5 & 23.2 & 1,360 & 2.66 & 1,380 \\
\hline MACCS2-M & 15.4 & 57.2 & 2.17 & 74.8 & 16.1 & 1,090 & 2.13 & 1,100 \\
\hline
\end{tabular}

models at a distance $700 \mathrm{~m}$ from the release point.

Inhalation dose showed the highest contribution, followed by cloudshine and groundshine. Moreover, inhalation dose showed the greatest difference according to models applied. With respect to the results for NRC-M, the effective doses of CNSC-M and MACCS2-M accounted for $60 \%$ and $47 \%$, respectively; for the thyroid doses of CNSC-M and MACCS2-M were $55 \%$ and $43 \%$, respectively. The difference of the results is mainly due to with or without deposition on the ground, and subsequent with or without depletion of plume depending on the models. In addition, it is due to different parameter values to be applied.

\section{Conclusion}

The entire process from model development to model validation of the ACCESS code was implemented exclusively with the domestically achieved technologies. In an applicative study, the predicted results by NRC-M were higher than those by other models in terms of total doses. The ACCESS code will be a useful tool for assessments of site suitability of NPPs, including heavy-water reactors.

\section{Acknowledgements}

This work was supported by Nuclear R\&D Programs of Ministry of Science, ICT and Future Planning of Korea (No. : 2012M2A8A4025914).

\section{References}

1. U. S. Nuclear Regulatory Commission. Atmospheric dispersion models for potential accident consequence assessments at nuclear power plants. Regulatory Guide 1.145. 1979;1-15.

2. Canadian Standards Association. Guidelines for calculating radiation doses to the public from a release of airborne radioactive material under hypothetical accident conditions in nuclear reactors. CAN/CSA- N288.2- M91. 1991;17-52.

3. Korean Nuclear Safety and Security Commission. Criteria for the investigation/evaluation regarding atmospheric condition on site of reactor facility. Notification No.2014-25 of the Nuclear Safety and Security Commission. 2014;1-16.

4. U. S. Department Of Energy. MACCS2 computer code application guidance for documented safety analysis. DOE-EH4.2.4.4MACCS2-Code Guidance. 2004;A1-A28.

5. International Commission on Radiological Protection. Recommendations of the International Commission on Radiological Protection. ICRP Publication 60. 1991;79-89. 